over content that is published on the website than with the old Vital website, which is exciting.

What have you learned from the relaunch? Have there been any issues you weren't expecting to face? I've learnt that launching a new online product with a new website and CPD scheme in less than half a year is incredibly difficult! Luckily our publisher, Rowena Milan, is highly capable and has led the project, bringing together the many different departments and individuals required to accomplish such a feat. I've helped where I can, but really articles and content are my forte!

What excites you most about BDJ Team?

The challenge of publishing monthly and generating articles that our readers want to read; hearing readers' feedback on the new publication; and making BDJ Team as popular, if not more popular, than Vital. I'm also looking forward to the official launch we are planning for the British Dental Conference and Exhibition in April.

\section{What can readers expect from BDJ Team?}

The style and tone of articles in $B D J$ Team will be exactly the same as those published in Vital - they will just be published more often! We will still have interviews, features, letters, news, products, advice, research and CPD relevant to DCPs.

How would you describe BDJ Team in one sentence?

$B D J$ Team is a UK-based online magazine publishing high quality content relevant to all members of the dental team. The strapline is: $B D J$ Team: at the heart of your practice.

If you or one of your team members would like to stay informed about BDJ Team, which will offer DCPs ten free hours of CPD this year, email bdjteam@nature.com and also visit www.nature.com/bdjteam.

\section{DENTAL ART}

\section{DENTISTRY THROUGH ART. PART 4}

The following images and descriptions are taken from dental students Rebecca Little and Lorna Hopps' fourth year elective project.

\section{Use of henbane}

Figure 1. Hyoscyamus niger (henbane) is a plant from the Solanaceae family which was used in England during the middle ages to create 'potions' due to its hallucinogenic effects. Here a man portrayed as a lord-like figure puts a healing hand on his subject who is humbly bowed over a smoking pot. The lord points a finger in a suggestive way of saying 'I can heal you' and sits on an elaborate chair. He was probably a physician/surgeon and would use henbane seeds to produce a worm-like ash to fool the patient into thinking the worm which had eaten his teeth had fallen out into the fire. The patient wears an anxious expression and the physician's lordly portrayal symbolises his position of importance. ${ }^{1,2}$

\section{Out hunting for teeth (A Caza De Dientes)}

Figure 2. A simple blacksmith leans over to extract a tooth from a flailing man whose limbs jerk out in pain and fear. The sculpture portrays the drama of the procedure from all sides. There are many intricate details in the sculpture - even including the nails of the patient. Since the sculpture is so detailed and realistic, it may be that the artist had seen this event take place and was recording the procedure. The positioning of the patient on the floor with his head between the dentist's knees was commonplace for an extraction and was not challenged until the late sixteenth century. ${ }^{1,3}$

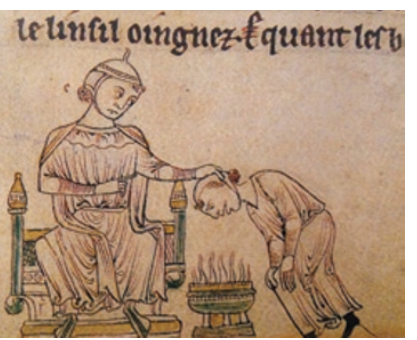

Fig. 1 Use of henbane. From an illuminated medieval manuscript, artist unknown. Around 13th century. From Roger of Salerno's Practica Chirurgia. Reproduced with permission from The Master and Fellows of Trinity College Cambridge

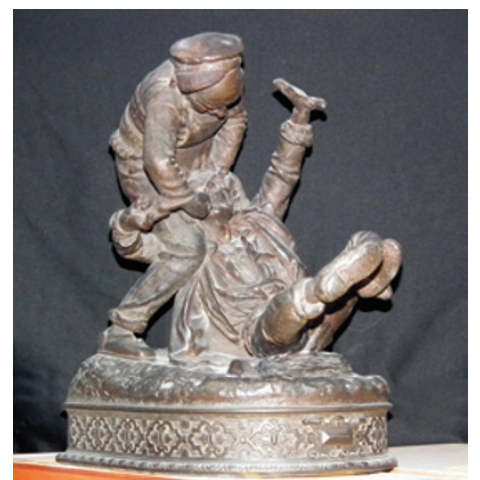

Fig. 2 The blacksmith dentist. Raimondo Pereda (1840-1915). Late 19 th century. Spelter alloy sculpture. Reproduced with permission from the RCSEd

1. Discussions with Dr Maureen Park and Professor David McGowan

2. Hillam C (ed). The roots of dentistry: for the Lindsay Society and for the history of dentistry. p 9. London: British Dental Journal, 1990.

3. Campbell J M. Catalogue of the Menzies Campbell Collection. p 122. Royal College of Surgeons of Edinburgh, 1966

\title{
SCOTLAND TO PROVIDE EXTRA FUNDS FOR TRAINING PRACTICES
}

NHS Education for Scotland (NES) is to fund additional educational resources to dental training practices which will further support the learning needs of the entire dental team and help them deliver safe, effective and person-centred care.

Learning materials will include an interactive programme on oral cancer and a suite of modules on communications skills.

David Felix, Postgraduate Dental Dean, NES said: 'NHS Education for Scotland greatly appreciates the commitment trainers make to supporting new graduates. These additional resources will allow all members of the practice to undertake verifiable CPD at a time and location of their choosing.

'We estimate each individual within the training practice could undertake between 15 and 20 hours of CPD, over a 15-month period. The intention is to give training practices appointed for the August 2014 to July 2015 training year priority access to these educational resources which will be free of charge.'

NES already develops, organises and delivers a variety of CPD opportunities for the entire dental team, enabling them to keep up to date and deliver high quality patient care. Some are delivered as team training events in practices, whilst others are delivered within the regional postgraduate centres.

The new resources will be supplied by a provider whose learning solutions are internationally acclaimed, with interactive content and media rich platforms for dental teams around the world.

www.nes.scot.nhs.uk 